\title{
SEJARAH PRODUCT XIAOMI
}

\author{
Anugrah Ananda Nauli Siregar \\ 185100014 \\ Fakultas Komputer \\ anugrahananda.student@umitra.ac.id
}

\begin{abstract}
Pada akhir-akhir ini, organisasi menjadi suatu hal yang sangat mudah didapati dalam kehidupan manusia. Salah satunya organisasi niaga yang berupa perusahaan begerak di bidang teknologi. Bidang ini memang menghasilkan beberapa organisasi niaga yang terkemuka di dunia. Mulai dari Google, Microsoft, Apple, LG, dll. Salah satu dari mereka saat ini menjadi booming dengan produk yang mereka luncurkan. Mereka tersebut adalah Xiaomi.

Xiaomi adalah salah satu perusahaan teknologi yang sedang berkembang pesat di dunia saat ini. Produk yang mereka keluarkan memang sangat baik dan kompetitif bagi persaingan di dunia teknologi abad ini, dan salah satu yang menjadi nilai plus yaitu harga miringnya. Hal ini mungkin menjadi salah satu pertanyaan terbesar bagi para penggunanya. Apakah isi kandungan xiaomi menggunakan barang bekas atau memang cara organisasi xiaomi menggunakan cara aneh yaitu tidak mengambil keuntungan secara besar bagi perusahaannya.

Memang inilah yang menjadi pertanyaan kontroversial bagi kalangan pengguna android tentang xiaomi. Tetapi, tidak bisa dipungkiri bahwa xiaomi adalah organisasi niaga teknologi terbesar ketiga dunia. Tentu kita ingin tahu, siapa pemilik dari xiaomi, bagaimana struktur organisasi mereka, bagaimana manajemen mereka, dll. Tentu, pertanyaan itu muncul dibenak pikiran kita semenjak keluarnya kata xiaomi dalam akhir-akhir ini. Mungkin pertanyaan ini dapat terjawab dalam makalah ini dan dapat mungkin dalam tanda ktip membantu kita mengetahui apa saja yang terkandung dalam organisasi xiaomi ataupun di dalam produk yang mereka pasarkan.
\end{abstract}

Kata Kunci : Xiaomi Organisasi Niaga Teknologi Terbesar Ketiga Dunia 
A. PENDAHULUAN

Xiaomi adalah perusahaan baru yang didirikan pada tanggal 6 Juni 2010 oleh seseorang bernama Lei Juni dengan gabungan beberapa perusahaan. Pada tahap pertama pendanaan inverstor institusi, termasuk Temasek, perusahaan investasi milik pemerintah Singapura, perusahaan pendanaan modal dari China IDS Capital dan Qiming Venture Partners, serta perusahaan pengembang prosesor Qualcomm. Pada 16 Agustus 2010, Xiaomi secara resmi meluncurkan ponsel pintar Android pertamanya yang memiliki antarmuka MIUI yaitu The MI 1 yang menganut system operasi berbasis android.

Pada musim keduanya sejak berdiri, Xiaomi semakin mengembangkan perangkat teknologi yang mereka akan pasarkan. Pada Agustus 2012, Xiaomi mengumkan peluncuran ponsel terbarunya MI2. Ponsel ini dioperasikan oleh prosesor Snapdragon S4 Pro APQ8064 milik Qualcomm, yang merupakan prosesor dengan empat inti dengan chip Krait berkecepatan $1.5 \mathrm{GHz}$, ponsel ini juga dilengkapi dengan RAM 2 GB dan GPU Adreno 320. Mungkin pada zamannya, smartphone ini cukup dan mampu menandingi ataupun melampaui smartphone pada zaman tersebut. Semenjak gebrakan smartphone tersebut,
Xiaomi seperti tidak ada pesaing. Banyak rekor-rekor penjualan smartphone yang dicetak oleh xiaomi.

Beberapa produk Xiaomi diproduksi oleh Foxconn, perusahaan perakit Iphone dan Ipad milik Apple. Pada 5 September 2013, Lei Jun, CEO Xiaomi, mengumumkan rencana perusahaan untuk meluncurkan TV Pintar 3D 47inch berbasis Andorid, yang akan dirait oleh pabrik yang memproduksi TV Sony yang berbasis di Taiwan, Wistron Corporation. Perusahaan mengumumkan alasannya dibalik keputusan ini karena ingin mengambil keuntungan dari kemampuan Wistron sebagai penyuplai produk Sony. Pada September 2013, perusahaan meluncurkan ponsel MI3 dalam dua versi, dengan satu versi yang dioperasikan oleh Snapdragon 800 (MSM8974AB) dan satu versi lainnya oleh NVIDIA's Tegra 4 chipset. Pada 25 September 2013, Xiaomi mengumumkan rencana perusahaan untuk membuka toko retail pertamanya di Beijing. Pada Oktober 2013, Xiaomi disebut sebagai ponsel pintar yang paling banyak digunakan kelima di China.

Pada tahun 2014, Xiaomi mulai melakukan ekspansi internasional dengan pertma kali mengunjungi Singapura. Dimulai dengan meluncurkan Redmi dan Mi3 pada masingmasing tangggal 21 Februari 
dan 7 Maret. Pada pembukaan tersebut, xiaomi melakukan rekor penjualan dengan Terbaru, Xiaomi mencetak rekor penjualan 5.000 phablet Xiaomi Redmi Note terjual hanya dalam 42 detik. Hal ini menunjukkan pembuktian Xiaomi untuk ekspansi seluruh dunia.

\section{B. PEMBAHASAN / STUDI KASUS}

Xiaomi inc. adalah sebuah perusahaan yang dimiliki pribadi yang mendesign, mengembangkan, dan menjual ponsel pintar, aplikasi, dan perangkat elektronik konsumer. Xiaomi adalah perusahaan mobile internet yang berdedikasi untuk menciptakan pengalaman pengguna dari segala aspek. Didirikan pada tahun 2010, perusahaan ini dengan cepat telah menjadi salah satu perusahaan teknologi terkemuka di Cina. Perusahaan ini kini bernilai lebih dari 10 miliar USD dan memiliki lebih dari 3000 karyawan. Kata xiaomi senidiri diambil dari Bahasa Tionghoa yaitu 小米科 技 ; pinyin:Xiăomì Kējì, yang secara harafiah "Teknologi Xiaomi". Xiaomi sendiri akhirakhir ini disebut sebagai produsen teknologi terbesar di Asia dan dunia dikarenakan keberhasilan mereka dalam memproduksi, mengembangkan, dan memasarkan produk mereka didalam bidang teknologi terutama dalam hal smartphone (ponsel pintar). Semenjak merilis ponsel pintar pertamanya pada Agustus 2011, Xiaomi telah mendapatkan pasar di daratan China dan terus mengembangkan produknya hingga perangkat elektronik konsumer lainnya. Selain itu, xiaomi mulai melakukan ekspansi penjualan teknologinya ke seluruh belahan dunia terutama pasar Negara berkembang. Hal ini dilakukan oleh Lei Jun yang menurut Forbes sebagai pria terkaya ke 23 dunia agar Xiaomi lebih dikenal luas oleh seluruh dunia dan agar tidak dibilang jago kandang. Strategi produk Xiaomi sering dikaitkan dengan strategi pemasaran Apple, sehingga Xiaomi sering disebut sebagai Apple-nya China

\section{c. ID SECURITY} QWTD4452377-ASP-5244107

\section{KESIMPULAN}

Xiaomi adalah suatu perusahaan yang bergerak di bidang teknologi berasal dari Negara Tiongkok yang menhasilkan beberapa smartphone yang cukup kompetitif di dunia saat ini. Dibangun pada tahun 2010, xiaomi menapaki tangga sukses dengan cepat tanpa halangan. Sang pendiri, Mr. Lei Jun, menggunakan etos kerja seperti orang Tionghoa yaitu giat, gigih tanpa putus asa ditambah 
dengan menganut system just for fun cukup membuat xiaomi dapat mengguncang dunia untuk saaat ini. Selain itu, struktur keorganisasian mereka yang menggunakan orangorang berpengalaman dibidangnya menjadi salah satu kesuksesan mereka saat ini lewat struktur kepengurusan mereka.

Selain itu, strategi pemasaran produk mereka yang hanya menggunakan online shop tanpa adanya iklan cukup mengsukseskan harga produk mereka yang dibilang cukup miring. Hal inilah yang membuat xiaomi semakin berjaya hingga saat ini. Padahal, perusahaan yang merakit smartphone sama seperti perusahaan yang merakit smartphone Apple. Hal inilah yang menjadi suatu cara unik yang dapat dilakukan dengan perusahaan teknologi lainnya agar dapat menyaingi raksasa teknologi lainnya. Hal inilah yang membuat xiaomi menjadi perusahaan teknologi cukup sukses dan menjanjikan di dunia untuk beberapa tahun kedepan.

\section{E. DISKUSI}

Apakah kamu tertarik dengan produk Xiaomi?

Adzriel Arraffi : Ya, saya sangat tertarik karena Xiaomi setiap tahunnya pasti mengeluarkan produk produk yang spesifikasi nya tidak kalah dengan produk lain. Mulai dari kebesarn RAM, internal, dan versi Android nya yang terbilang gahar itu yang membuat saya tertarik. Semenjak saya membaca dan meneliti artikel ini, saya memulai ber niat untuk menabung dari kini untuk membeli produk dari perusahaan Xiaomi. 


\section{F. REFERENCE}

[1] O. M. Febriani and A. S. Putra, "Sistem Informasi Monitoring Inventori Barang Pada Balai Riset Standardisasi Industri Bandar Lampung,” J. Inform., vol. 13, no. 1, pp. 90-98, 2014.

[2] A. S. Putra, "Paperplain: Execution Fundamental Create Application With Borland Delphi 7.0 University Of Mitra Indonesia,” 2018.

[3] A. S. Putra, "2018 Artikel Struktur Data, Audit Dan Jaringan Komputer,” 2018.

[4] A. S. Putra, "ALIAS MANAGER USED IN DATABASE DESKTOP STUDI CASE DB DEMOS.”

[5] A. S. Putra, "COMPREHENSIVE SET OF PROFESSIONAL FOR DISTRIBUTE COMPUTING.”

[6] A. S. Putra, "DATA ORIENTED RECOGNITION IN BORLAND DELPHI 7.0.”
[7] A. S. Putra, "EMBARCADERO DELPHI XE 2 IN GPUPOWERED FIREMONKEY APPLICATION.”

[8] A. S. Putra, "HAK ATAS KEKAYAAN INTELEKTUAL DALAM DUNIA TEKNOLOGY BERBASIS REVOLUSI INDUSTRI 4.0.”

[9] A. S. Putra, "IMPLEMENTASI PERATURAN PERUNDANGAN UU. NO 31 TAHUN 2000 TENTANG DESAIN INDUSTRI BERBASIS INFORMATION TECHNOLOGY.”

[10] A. S. Putra, "IMPLEMENTATION OF PARADOX DBASE."

[11] A. S. Putra, "IMPLEMENTATION OF TRADE SECRET CASE STUDY SAMSUNG MOBILE PHONE."

[12] A. S. Putra, "IMPLEMENTATION PATENT FOR APPLICATION WEB BASED CASE STUDI WWW. PUBLIKLAMPUNG. COM."

[13] A. S. Putra, "IMPLEMENTATION SYSTEM FIRST TO INVENT IN DIGITALLY INDUSTRY."

[14] A. S. Putra, "MANUAL REPORT \& INTEGRATED DEVELOPMENT

ENVIRONMENT BORLAND DELPHI 7.0.”

[15] A. S. Putra, "PATENT AS RELEVAN SUPPORT RESEARCH.”

[16] A. S. Putra, "PATENT FOR RESEARCH STUDY CASE OF APPLE. Inc.” 
[17] A. S. Putra, "PATENT PROTECTION FOR APPLICATION INVENT."

[18] A. S. Putra, "QUICK REPORT IN PROPERTY PROGRAMMING."

[19] A. S. Putra, "REVIEW CIRCUIT LAYOUT COMPONENT

REQUIREMENT ON ASUS NOTEBOOK."

[20] A. S. Putra, "REVIEW TRADEMARK PATENT FOR INDUSTRIAL TECHNOLOGY BASED 4.0.”

[21] A. S. Putra, "TOOLBAR COMPONENT PALLETTE IN OBJECT ORIENTED PROGRAMMING."

[22] A. S. Putra, "WORKING DIRECTORY SET FOR PARADOX 7.”

[23] A. S. Putra, "ZQUERY CONNECTION

IMPLEMENTED

PROGRAMMING STUDI CASE PT. BANK BCA Tbk."

[24] A. S. Putra, D. R. Aryanti, and I. Hartati, "Metode SAW (Simple Additive Weighting) sebagai Sistem Pendukung Keputusan Guru Berprestasi (Studi Kasus: SMK Global Surya)," in Prosiding Seminar Nasional Darmajaya, 2018, vol. 1, no. 1, pp. 85-97.

[25] A. S. Putra and O. M. Febriani, "Knowledge Management Online Application in PDAM Lampung Province," in Prosiding International conference on Information Technology and Business (ICITB), 2018, pp. 181-187.

[26] A. S. Putra, O. M. Febriani, and
B. Bachry, "Implementasi Genetic Fuzzy System Untuk Mengidentifikasi Hasil Curian Kendaraan Bermotor Di Polda Lampung," SIMADA (Jurnal Sist. Inf. dan Manaj. Basis Data), vol. 1, no. 1, pp. 21-30, 2018.

[27] A. S. Putra, H. Sukri, and K. Zuhri, "Sistem Monitoring Realtime Jaringan Irigasi Desa (JIDES) Dengan Konsep Jaringan Sensor Nirkabel," IJEIS (Indonesian J. Electron. Instrum. Syst., vol. 8, no. 2, pp. 221-232.

[28] D. P. Sari, O. M. Febriani, and A. S. Putra, "Perancangan Sistem Informasi SDM Berprestasi pada SD Global Surya," in Prosiding Seminar Nasional Darmajaya, 2018, vol. 1, no. 1, pp. 289-294. 